\title{
Correspondence
}

\section{Oesophageal pressure measurements in ventilated preterm babies}

Sir,

Drs Greenough and Morley ${ }^{1}$ conclude that very little ventilator pressure is transmitted to the oesophageal balloon in paralysed babies because of low lung compliance, and support this by showing lack of transmission to chest drains inserted in 2 babies with pneumothorax. Although this fits well with their other observations, they did not say whether there was any intrapleural air remaining on the chest $x$-ray film at the time of recording. The compliance of an isolated sealed pocket of air under pressure, say in the mediastinum, could be lower than either lungs or chest wall and could provide a significant artefact in their results.

\section{Reference}

1 Greenough A, Morley CJ. Oesophageal pressure measurements in ventilated preterm babies. Arch Dis Child 1982; 57: $851-5$.

Jo Poulton

John Radcliffe Hospital, Headington, Oxford $O X 39 D U$

Sir,

The study of Greenough and Morley ${ }^{1}$ is interesting in more than one aspect. To our knowledge Fig. $2^{1}$ of that paper is the first demonstration by means of intrapleural pressure recording of the inspiratory augmenting or Head's reflex ${ }^{2}{ }^{3}$ in ventilated preterm infants.

The Head's reflex has been described in newborn infants mainly in association with the first breath. ${ }^{4}$ The influence of gestational age both on Head's reflex and the inspiratory inhibitory reflex (Hering-Breuer reflex) has recently been reviewed by Trippenbach. ${ }^{6}$ In our experience preterm infants are not only more likely to accept rhythmic inflation, but also respond with better inspiration. This is shown by the impedance pneumatogram of an infant of 29 weeks' gestational age on intermittent mandatory ventilation (Figure) and in Fig. 2 of
Greenough and Morley's paper. We seldom observed an enhanced inspiration pattern in a near term or term infant. More often the term infant is fighting against the ventilator, because of a more active Hering-Breuer reflex. Apart from gestational age, however, the low flow rate (5 1/min) used by Greenough and Morley might account for the elicitation of the paradoxical sigh, so nicely shown in that study.

The response of some preterm infants to intermittent mandatory volume ventilation by augmented inspiration bears some practical implications in neonatal respiratory care. In addition to the temporary increase in the functional residual capacity ${ }^{7}$ it offers further arguments for the usefulness of intermittent mandatory ventilation and the limited benefit offered by a synchronised mandatory ventilation modus. Furthermore, the Head's reflex in conjunction with intermittent mandatory ventilation neutralises the negative influences of positive pressure ventilation on the circulation. Finally, it explains why, in some instances, curarisation has a deleterious effect on the oxygenation of the preterm ventilated infant. ${ }^{8}$

The technique suggested by Greenough and Morley will help to define the equivocal clinical concept of 'fighting against the ventilator'. More studies are needed to determine the optimal conditions (flow-rate, peak pressure, etc) to elicit the Head's reflex in ventilated preterm infants.

\section{References}

1 Greenough A, Morley CJ. Oesophageal pressure measurements in ventilated preterm babies. Arch Dis Child 1982; 57: $851-5$.

2 Head H. On the regulation of respiration. J Physiol 1889; 10: 1-70.

3 Widdicombe JG. Head's paradoxical reflex. $Q J$ Exp Physiol 1967; 52: 44-50.

4 Cross KW, Klaus M, Tooley WH, Weisser K. The response of the new-born baby to inflation of the lungs. J Physiol 1960; 151: 551-65.

5 Boon AW, Milner AD, Hopkin IE. Physiological responses of the newborn infant to resuscitation. Arch Dis Child 1979; 54: 492-8.

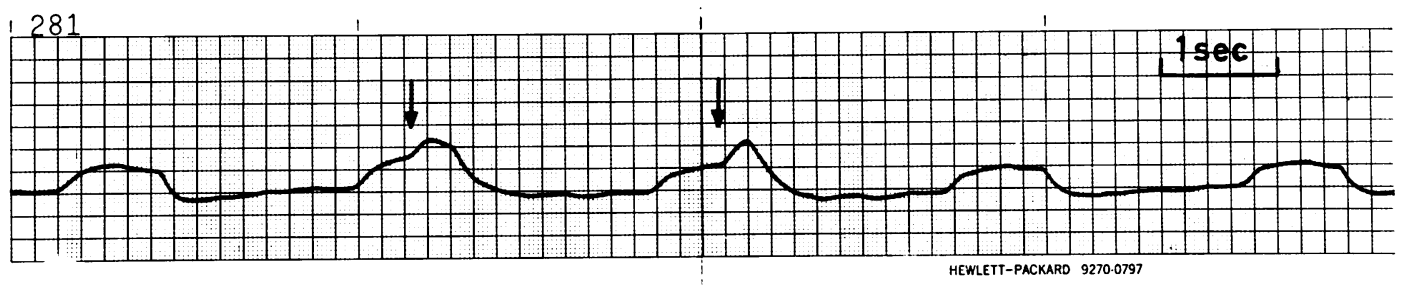

Figure Impedance pneumatogram of a 29 weeks' gestational age newborn infant ventilated on intermittent mandatory ventilation modus (flow rate $5 \mathrm{l} / \mathrm{min}$ ). The enhanced inspiration (arrows) in two out of five inflations is clearly seen. The observation can be done with the use of routine clinical monitoring equipment. 
B Trippenbach T. Laryngeal, vagal, and intercostal reflexes during the early postnatal period. J Dev Physiol 1981; 3: 133-59.

7 Shutack JG, Fox WW, Shaffer TH, Schwartz JG, Moomjian AS. Effect of low-rate intermittent mandatory ventilation on pulmonary function of low-birth-weight infant. J Pediatr 1982; 100: 799-802.

8 Pollitzer MJ, Reynolds EOR, Shaw DG, Thomas RM. Pancuronium during mechanical ventilation speeds recovery of lungs of infants with hyaline membrane disease. Lancet $1981 ; 1$ : 346-8.

H DeVlieger, J JAeKen, P CASAER, AND E EgGERMONT, Neonatal Intensive Care Unit, Department of Paediatrics, University Hospital Gasthuisberg, Leuven, Belgium

\section{Dr Greenough comments:}

We are grateful to Devlieger et al. for showing interest in our demonstration that Head's reflex can be provoked by intermittent positive pressure ventilation in very preterm babies. We have now studied in detail the stimulating and moderating factors of this reflex in $\mathbf{4 0}$ ventilated preterm babies (a preliminary report was published in $1982^{1}$ ).

In summary, augmented inspirations were seen only in neonates ventilated at frequencies less than or equal to 15 per minute. Although this reflex was seen at all the gestational ages studied (24-36 weeks) it could not be elicited after the fifth postnatal day. The frequency of occurrence of the reflex was inversely related to the dynamic compliance, as was the ventilator pressure necessary to stimulate this 'paradoxical response'. It always occurred early in ventilator inflation, within 0.2 seconds from the onset, and 'provoking' ventilator volume was remarkably similar in all babies when related to bodyweight $-5 \cdot 72 \pm 1 \cdot 1 \mathrm{ml} / \mathrm{kg}$ (mean $\pm \mathrm{SD}$ ). Babies who showed a higher frequency of this reflex than might have been expected from their lung compliance, appeared to benefit by requiring shorter periods of ventilation. In consequence any technique which could enhance the elicitation of this reflex should improve ventilation of such babies.

These studies show that the way in which the baby's spontaneous respiration interacts with the respirator is very important. Babies are not always passive recipients of ventilation, nor do they consistently fight the ventilator. These phenomena deserve to be studied in more depth if we are to improve our knowledge and techniques of neonatal ventilation.

We thank Dr Poulton for her comments, during none of the reported recordings was there any intrapleural air remaining on the chest $x$-ray film.

\section{References}

1 Greenough A, Morley CJ. Factors stimulating Head's reflex in ventilated premature babies $J$ Physiol 1982; 332: 37.

\section{Transient pseudo-precocious puberty by probable oestrogen intake in 3 girls}

Sir,

I was interested to read this account but I would dispute the view that the ingestion of an unidentified oestrogen was probably the cause of transient pseudo-precocious puberty. The clinical features in all 3 girls would be consistent with those caused by a follicular cyst of the ovary which had undergone spontaneous rupture, thus leading to withdrawal bleeding and low plasma oestradiol values at the time of investigation. Such cysts may be freely mobile and very difficult to detect on clinical examination. However, they can be readily demonstrated by sonography, a technique which is useful in the assessment of female precocious puberty.

DB GRANT

The Hospital for Sick Children, Gt Ormond Street, London WCIN 3JH

\section{Guidance of ventricular tap by ultrasound}

Sir,

The interesting article of Levene deals with the advantage of ventricular punctures by ultrasound. We use a mechanical sectorscanner (ADR-Kranzbühler) in our department. It is fitted with a short-focus $3 \mathrm{MHz}$ transducer. An adaptor is attached to the head which allows a needle to be directed obliquely in the ultrasound field. During the puncture the needle tip is continuously monitored on the TV screen as it penetrates into the tissues. Before the puncture both the transducer head and the adapter are

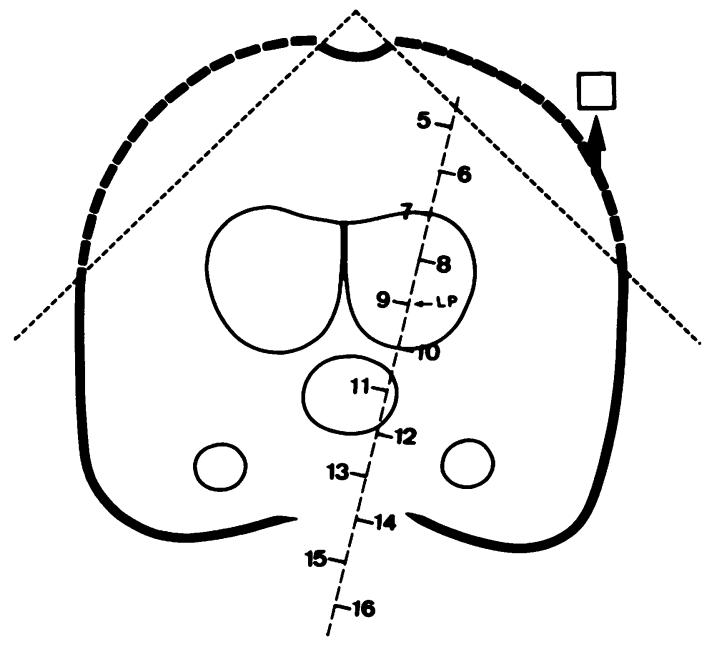

Fig. 1 Schematic representation of a coronal cross-section of the brain. TV screen is covered with a transparency, delineating the ultrasound field and the puncture needle traject with distance markings. 